
of Engineers ${ }_{\circledast}$

Engineer Research and

Development Center

\title{
A Technique to Propagate Clitoria fragrans from Xylopodia
}

Timothy J. Cary, Terry L. Bashore, Laura M. Leavitt, and

March 2015

Antonio J. Palazzo

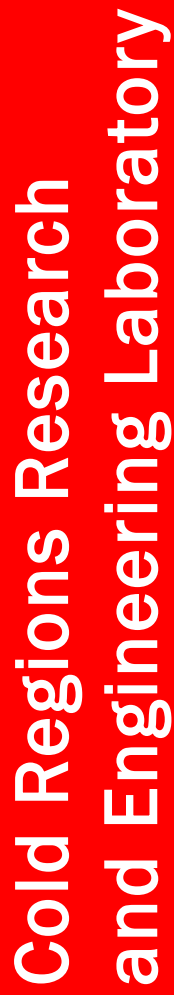

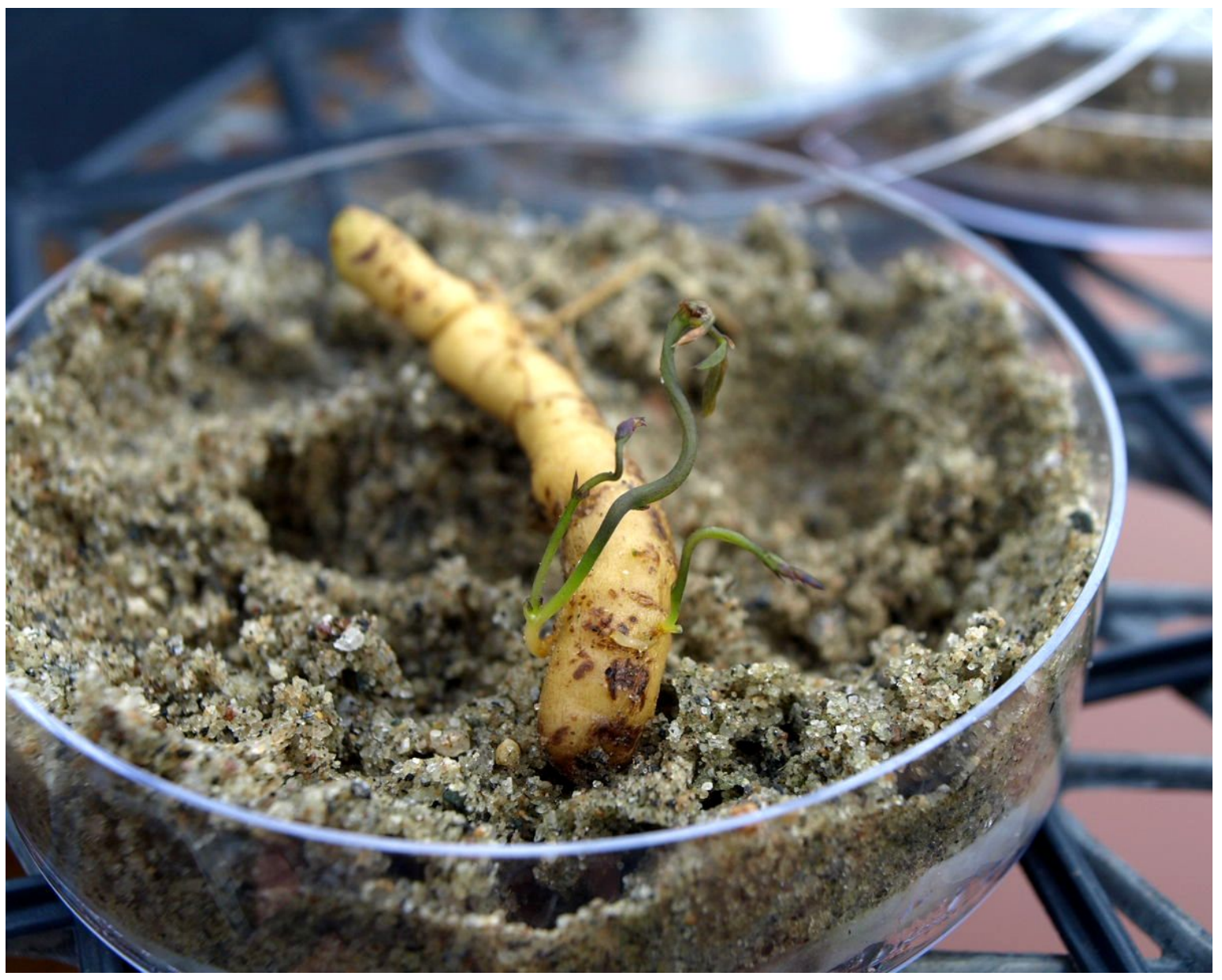


The U.S. Army Engineer Research and Development Center (ERDC) solves the nation's toughest engineering and environmental challenges. ERDC develops innovative solutions in civil and military engineering, geospatial sciences, water resources, and environmental sciences for the Army, the Department of Defense, civilian agencies, and our nation's public good. Find out more at www.erdc.usace.army.mil.

To search for other technical reports published by ERDC, visit the ERDC online library at http:// acwc.sdp.sirsi.net/ client/ default. 


\section{A Technique to Propagate Clitoria fragrans from Xylopodia}

Timothy J. Cary and Laura M. Leavitt

Cold Regions Research and Engineering Laboratory (CRREL)

U.S. Army Engineer Research and Development Center (ERDC)

72 Lyme Road

Hanover, NH 03755

Terry L. Bashore

Headquarters Air Combat Command (ACC)

Ranges, Airspace and Airfield Operations Division (HQ ACC/A3A)

205 Dodd Blvd, Suite 101

Langley Air Force Base, VA 23665-2789

Antonio J. Palazzo

Oak Ridge Institute for Science and Education

4692 Millennium Drive, Suite 101

Belcamp, MD 21017

Final Report

Approved for public release; distribution is unlimited.

Prepared for Ranges, Airspace and Airfield Operations Division

Headquarters Air Combat Command

Langley Air Force Base, VA 23665-2789

Under Project F2QF270137G002, “Pigeon wings restoration at Avon Park Air Force Range" 


\section{Abstract}

Clitoria fragrans (pigeon wings), is a limited seed producer and a federally listed threatened plant. Therefore, we conducted a greenhouse study to determine whether $\mathrm{C}$. fragrans can be propagated vegetatively from xylopodia and whether grouth hormones can enhance propagation success. This information could be used to maintain population viability in the future. For this study, we collected mature plants from the field, transplanted them in the greenhouse, and harvested xylopodia from the root system. We treated the xylopodia with indole-3-acetic acid (IAA) or indolebutyric acid (IBA) at concentrations of 0, 250, 500, 1000, and 2000 $\mathrm{mg} / \mathrm{L}$ for the lateral root xylopodia and at 0 and $1000 \mathrm{mg} / \mathrm{L}$ IAA for the terminal xylopodia. We observed the xylopodia for 114 days for signs of root growth, newly developed shoots, mold, and rot. Lateral xylopodia controls and those treated with IAA produced new plants, though propagation was inversely proportional to the treatment level of IAA. Two of the nine treated terminal xylopodia produced new plants. No plants were propagated from the IBA treatments. Propagating C. fragrans is possible and has potential to be a viable method for reestablishing the plant in the field. A total of 19 plants were produced in this study from only two initial C. fragrans plants.

DISCLAIMER: The contents of this report are not to be used for advertising, publication, or promotional purposes. Citation of trade names does not constitute an official endorsement or approval of the use of such commercial products. All product names and trademarks cited are the property of their respective owners. The findings of this report are not to be construed as an official Department of the Army position unless so designated by other authorized documents. 


\section{Contents}

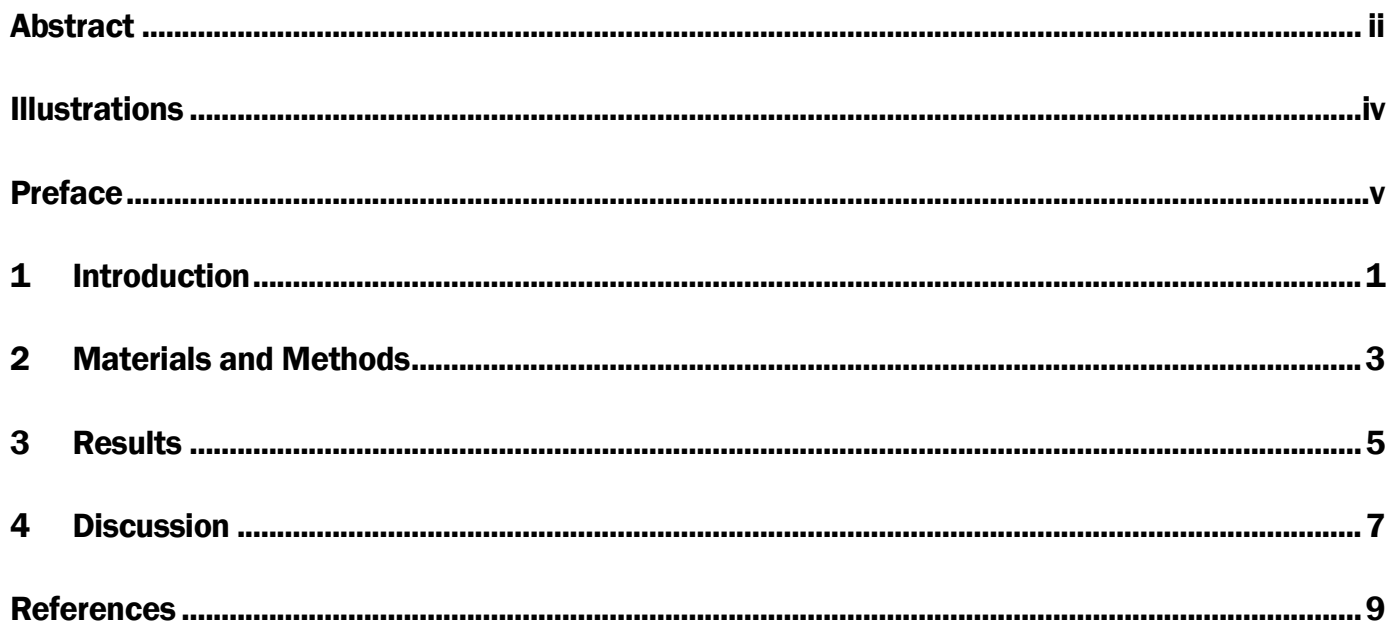

Report Documentation Page 


\section{Illustrations}

\section{Figures}

1 Lateral xylopodia after 10 weeks of IAA treatment of $250 \mathrm{ppm}$ (left) and 500 ppm (right).

\section{Tables}

1 By hormone treatment, the number of lateral xylopodia that produced new plants, only roots, or no stems nor roots ......................................................................... 5

2 By hormone treatment, the number of terminal xylopodia that produced new plants, only roots, or no stems nor roots. 


\section{Preface}

This study was conducted for the U.S. Air Force, Headquarters Air Combat Command, Ranges, Airspace, Ranges, and Airfield Operations Division, Langley Air Force Base, under Project F2QF270137G002, "Pigeon wings restoration at Avon Park Air Force Range."

The work was performed by Timothy J . Cary and Laura Leavitt (Biogeochemical Sciences Branch, Dr. J ustin Berman, Chief), U.S. Army Engineer Research and Development Center, Cold Regions Research and Engineering Laboratory (ERDC-CRREL); Dr. Terry L. Bashore, U.S. Air Force, Headquarters Air Combat Command, Ranges, Airspace and Airfield Operations Division, Langley Air Force Base; and Antonio J . Palazzo, Oak Ridge Institute for Science and Education. At the time of publication, Dr. Loren Wehmeyer was Acting Chief of the Research and Engineering Division of ERDC-CRREL. The Deputy Director of ERDC-CRREL was Dr. Lance Hansen, and the Director was Dr. Robert Davis.

The authors wish to acknowledge Steve Orzell and Paul Ebersbach, Avon Park Air Force Range, for their scientific and technical support.

LTCJ ohn Tucker was the Acting Commander of ERDC, and Dr. J effery P. Holland was the Director. 


\section{Introduction}

The Endangered Species Act (U.S. Congress 1973) requires protection and conservation of federally listed threatened and endangered plants and animals and their habitats. United States Air Force installations are required (USAF 2004) to sustain federally listed threatened and endangered species and to take steps to conserve species facing extinction. To maintain adequate populations of endangered or threatened plant species, especially those whose sexual propagation is limited by inadequate seed numbers, dormancy, viability, and environmental sensitivity, alternative propagation techniques need to be investigated. Asexual propagation techniques have an advantage in that genetic resources are maintained and the process can be accomplished in a controlled environment.

Clitoria fragrans (pigeon wings) is a limited seed producer and a federally listed threatened plant (U.S. Fish and Wildlife Service [USFWS] 1993). It inhabits, but is poorly distributed within, the Florida scrub. It is endemic to the Lake Wales Ridge, a $160 \mathrm{~km}$ long, narrow ridge in south central Florida that runs through the Avon Park Air Force Range (APAFR) in Highlands and Polk Counties (Palazzo et al. 2006; Fantz 1977; Wunderlin et al. 1980). Unpublished data from APAFR (S. Orzell, pers. comm., APAFR, J anuary 2014) notes that C. fragrans is found in 5 of 52 soil types and only 659 out of 43157 ha (5.0\%) at APAFR. About $85 \%$ of the original scrub habitat has been lost (Christman and J udd 1990) along the Lake Wales Ridge. Habitat fragmentation due to conversion of native habitat for citrus groves and residential areas is the main threat to this species (USFWS 1993).

USFWS (1999) indicates that C. fragrans preferentially occupy sites characterized by frequent fire. However, Weekley and Menges (2003) documented the fire responses of $\mathrm{C}$. fragrans and noted surprisingly low levels of sprouting after fire, with a survival rate near $50 \%$ when sprouting. Lewis (2007) reported that time since the last fire had a significant negative effect on the number of individuals in populations; however, plant density showed no relationship with time since the last fire.

Fantz (1977) reported that C. fragrans can sprout from subterranean storage structures called "tubers or xylopodia," which are 4- $10 \mathrm{~mm}$ thick, 5- 
$15 \mathrm{~mm}$ long, and composed of lignose or woody type material. Observations from our studies with $\mathrm{C}$. fragrans indicate rooting appears random through the soil profile. The xylopodia are present throughout the entire root system and form as the root system develops. Fantz (1977) also states that one to several stems may originate from a single xylopodia. New plant emergence appears to occur in the spring, and fruit is produced primarily from May to J une (Fantz 1977). New aerial stems from xylopodia are erect and purplish.

Other plant species have also been reported to propagate through xylopodia. Wallnöfer (1997) reported the woody plants Styrax maninul and S. pedicellatum growing in drought- and fire-adapted tropical savannas form xylopodia and have a strong capacity to develop sprouts. The author suggested formation of the xylopodia is genetically controlled. Palhares et al. (2007) found for the species Brosimumgaudi chaudii that the xylopodia was a strategy to survive fire as, they suggested, it had a higher capacity for water retention.

Using seed of C. fragrans to increase plant numbers in the field is problematic because of the low number of seeds per plant and the difficulty in collecting viable seeds. Mature plants produce only a few seeds. The number of seedpods per plant we observed ranged from zero to four, and there were only three to five seeds per pod. Therefore, collecting sufficient seeds to develop an extensive restoration program would be difficult. Also, when seeds become viable, they burst from the pods, making collection difficult (Lewis 2007). Seeds collected before bursting were not found to be viable (T. Cary, pers. comm.).

Asexual propagation techniques include the use of auxins to stimulate new plant production. Indole-3-acetic acid (IAA) and indolebutyric acid (IBA) are two commonly used auxins to stimulate root and shoot growth (Starbuck and Preczewski 1986; and Gravel et al. 2007). Our objective in this study was to determine whether $\mathrm{C}$. fragrans could be propagated vegetatively from xylopodia and whether grouth hormones enhanced propagation success. This information can help to develop a technique to maintain population viability. 


\section{Materials and Methods}

The Engineering Research and Development Center's Cold Regions Research and Engineering Laboratory (ERDC-CRREL) and APAFR staff collected C. fragrans plants from APAFR's Alpha Range $\left(27^{\circ} 39^{\prime} \mathrm{N}\right.$ and $81^{\circ} 16^{\prime}$ W) on 25J une 2007. Plants were placed in plastic bags containing moistened paper towels and temporarily stored in ice-cooled containers. Typical plants at the time of collection contained between zero and four xylopodia (tubers) per plant. The soils at the site were either Daytona or Narcoossee Sand, or both. The dominant vegetation in the area was oak (Quercus spp.) and palmetto (Serenoa repens). The harvested plants were transferred to the ERDC-CRREL greenhouse in Hanover, NH, on 26 J une 2007. All plants were live when collected and when they arrived at the greenhouse. Individual plants were placed in trays measuring $128 \mathrm{~cm}$ long, $70 \mathrm{~cm}$ wide, and $15 \mathrm{~cm}$ deep; covered with sand; and watered to keep the sand moist. Plants remained in the trays until harvested for this study. The plants received approximately $250 \mathrm{~mL}$ of water daily.

On $3 \mathrm{~J}$ anuary 2013, or about five years after being transferred from the field to the greenhouse, two plants were selected from the trays and washed to remove the sand from the roots. Xylopodia were present along the main taproot and on lateral roots and were of various sizes from 2 to 5 $\mathrm{cm}$ in length. Both plants also contained a xylopodia at the crown of the plant. Xylopodia appeared to form at random along the individual roots within the entire root system. Younger roots or root ends had smaller or no xylopodia. We also noted a similar growth aspect of the roots and xylopodia during previous field collections. Xylopodia were physically separated into two groups: those originating from terminal roots and those from lateral roots. Most xylopodia were light brown in color with some having black spots.

We collected 72 xylopodia from lateral roots and divided them into nine treatments-control (distilled water), 250 IAA, 500 IAA, 1000 IAA, 2000 IAA, 250 IBA, 500 IBA, 1000 IBA, and 2000 IBA - with eight replications. We also collected 12 xylopodia from the terminal roots. Due to the insufficient numbers, they were treated with only distilled water and $1000 \mathrm{mg} / \mathrm{L}$ of IAA. There were nine replications of the $1000 \mathrm{mg} / \mathrm{L}$ treatment and three replications of the control treatments. We separated whole 
xylopodia with a razor blade and removed all fine root hairs, placing the individual xylopodia in the desired hormone treatment solution or distilled water for five minutes. We selected xylopodia of similar size and placed them on filter paper contained in an $8 \mathrm{~cm}$ diameter plastic petri plate and then covered them with builder's sand, which we covered with an additional piece of filter paper. We placed the petri plates on a bench in the greenhouse where they were randomized weekly, periodically monitored for the emergence of new plants, and checked daily for moisture content. Water was added as needed to maintain soil saturation.

When we noted white mold, we cleansed the xylopodia by spraying it with distilled water, changed the bottom level filter paper, and replaced the sand. Later, after about two weeks, as the mold kept occurring, we permanently removed the top layer of filter paper from all treatments. To identify the mold we scrapped the xylopodia surface into a small vial of phosphate buffered saline ( $1 \mathrm{~mL})$; shook it for 2 minutes; placed a drop onto a $10 \mathrm{\mu l}$ microscope slide, covering it with a slip and sealing it with nail polish; and imaged it under phase contrast via light transmission.

We observed the xylopodia six times, at days 19, 26, 54, 68, 89, and 114, for any signs of root growth, newly developed shoots, mold, and rot (Figure 1). When we noted new shoots emerging from the xylopodia, we transferred the plants to $15 \mathrm{~cm}$ plastic pots containing builder's sand.

Figure 1. Lateral xylopodia after 10 weeks of IAA treatment of $250 \mathrm{ppm}$ (/eft) and $500 \mathrm{ppm}$ (right).

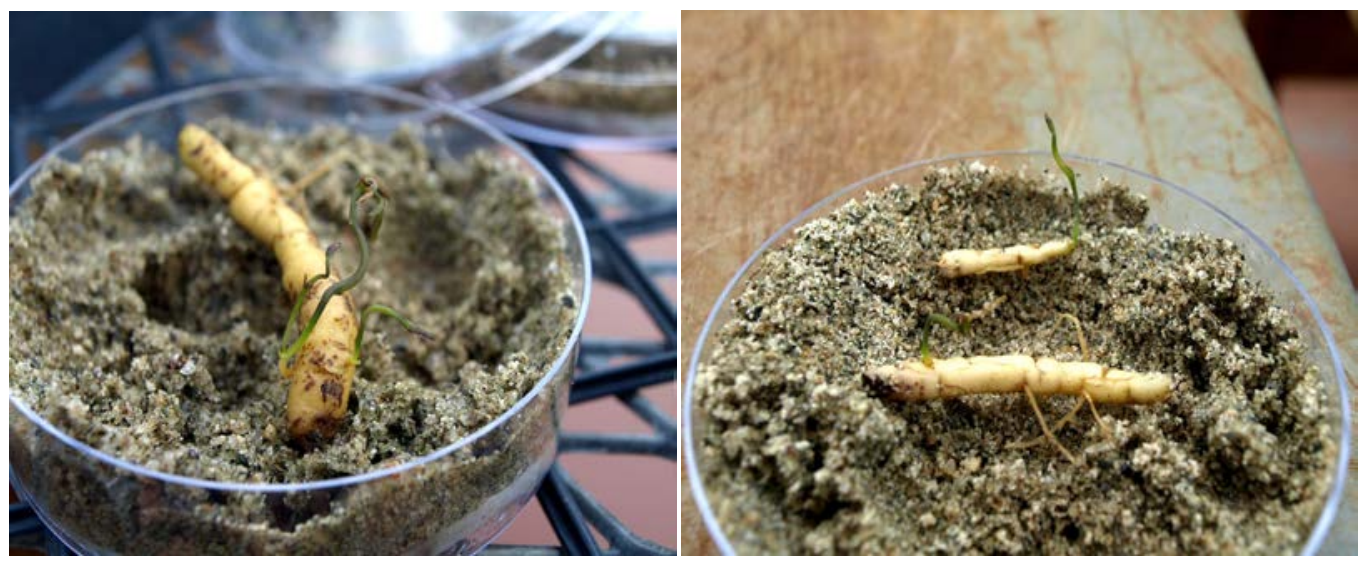




\section{Results}

Only xylopodia treated with IAA or distilled water produced new plants. The number of new plants for each IAA treatment was 5, 2, 3, and 0 for the 250, 500, 1000, and $2000 \mathrm{mg} / \mathrm{L}$ treatments, respectively (Table 1). The success in propagation was inversely proportional to the treatment level of IAA. Six of the eight xylopodia in the highest treatment rotted. In the controls, half produced new plants and the other half rotted.

Table 1. By hormone treatment, the number of lateral xylopodia that produced new plants, only roots, or no stems nor roots.

\begin{tabular}{|l|c|r|c|c|c|}
\hline \multicolumn{1}{|c|}{ Treatment } & $\begin{array}{c}\text { Number of } \\
\text { Replications }\end{array}$ & $\mathrm{mg} / \mathrm{L}$ & New Plants & Only Roots & $\begin{array}{c}\text { No Stems and } \\
\text { No Roots }\end{array}$ \\
\hline IAA & 8 & 250 & 5 & 0 & 3 \\
\hline IAA & 8 & 500 & 2 & 2 & 4 \\
\hline IAA & 8 & 1000 & 3 & 2 & 2 \\
\hline IAA & 8 & 2000 & 0 & 3 & 5 \\
\hline IBA & 8 & 250 & 0 & 4 & 4 \\
\hline IBA & 8 & 500 & 0 & 8 & 0 \\
\hline IBA & 8 & 1000 & 0 & 3 & 5 \\
\hline IBA & 8 & 2000 & 0 & 0 & 8 \\
\hline Distilled $\mathrm{H}_{2} \mathrm{O}$ & 8 & 0 & 4 & 0 & 4 \\
\hline
\end{tabular}

We periodically recorded the emergence of new plants, starting on day 19 after transferring xylopodia to petri plates till day 114. The timing of the emergence of new plants was again inversely proportional to the IAA concentration. Half of the replications produced new plants within 68 days after placement in petri dishes in the lowest treatment of $250 \mathrm{mg} / \mathrm{L}$, and an additional plant emerged after 89 days. In the $500 \mathrm{mg} / \mathrm{L}$ treatment, one plant emerged at each of the 68 and 89-day recording periods. In the $1000 \mathrm{mg} / \mathrm{L}$ treatment, one plant emerged at 68 days and two at 114 days. There were no plants produced at the $2000 \mathrm{mg} / \mathrm{L}$ treatment.

No plants propagated from the IBA treatments. Of the 32 IBA-treated xylopodia tested, 20 had rotted; and the occurrence of rot appeared to increase with the increase in concentration of IBA. All eight replications rotted in the highest treatment. However, some of the replications were able to produce roots in all treatments except at the $2000 \mathrm{mg} / \mathrm{L}$ level (Table 1). 
Of the nine IAA treated terminal xylopodia (Table 2), two xylopodia produced new plants at 89 and 114 days after treatment; four rotted; and five produced roots, including those that produced plants. The three control xylopodia all produced roots and plants.

Table 2. By hormone treatment, the number of terminal xylopodia that produced new plants, only roots, or no stems nor roots.

\begin{tabular}{|l|c|c|c|c|c|}
\hline \multicolumn{1}{|c|}{ Treatment } & $\begin{array}{c}\text { Number of } \\
\text { Replications }\end{array}$ & $\mathrm{mg} / \mathrm{L}$ & New Plants & Only Roots & $\begin{array}{c}\text { No Stems and } \\
\text { No Roots }\end{array}$ \\
\hline IAA & 9 & 1000 & 2 & 3 & 4 \\
\hline Distilled $\mathrm{H}_{2} \mathrm{O}$ & 3 & 0 & 3 & 0 & 0 \\
\hline
\end{tabular}

We recorded the emergence of roots from the xylopodia to determine if this trait was indicative of plant emergence (Tables 1 and 2). All xylopodia that produced plants also produced roots; however, root emergence on its own was not indicative of plant emergence.

We observed white mold soon after placing the xylopodia into the petri plates. The mold was subjected to microscopic analysis, as described above; and we determined that it was a combination of fusarium and rhizoctonia. 


\section{Discussion}

We were able to propagate new plants from xylopodia collected from both lateral and terminal roots below the soil surface. Approximately $50 \%$ of the lateral xylopodia sprouted new plants in the control and in the 250 mg/ L IAA treatments; and for the terminal xylopodia, all three controls produced new plants. This emergence of new plants from xylopodia may partially explain how plants sprout in the field and supports the results of Weekley and Menges (2003) who found nearly $50 \%$ of C. fragrans successfully sprouting after a fire in the field. The added benefit to greenhouse propagation is that the numbers of plants propagated are known and their genetic resources are maintained.

The application of IAA and IBA at the concentrations used in this study did not increase over the control the number of plants propagated, thus distilled water is just as effective as using more expensive auxins and is less labor intensive. In fact, one could consider IBA to be detrimental at the higher levels used in this study. Though both IAA and IBA are plant auxins known to facilitate plant emergence and development, there is little information of the many aspects of their mechanisms of action and the extent to which they contribute to auxin-regulated plant development (Simon and Petrášek 2011; Zhao 2010); and their biosynthesis in plants is extremely complex (Zhao 2010). In this study, we found that there is some inhibitory effect from the higher concentrations; and further study is needed at lower concentrations or mixtures of IAA and IBA. The IBA treatments did not produce any plants but did show root development; IBA is known for the induction of adventitious roots (Ludwig-Müller 2000).

The technique described in this report is relatively easy to conduct as is explained in the "Materials and Methods" section. However, important greenhouse propagation procedures to focus on include removing the xylopodia from the root system, controlling mold, and timing plant emergence. The origination of the rot is unknown but could partially be related to xylopodia damage during cutting. Xylopodia should be cut cleanly with a sharp instrument to avoid damage that could lead to rot. We had issues with xylopodia rot in all treatments including the control, and we believe 
the rot was related to our procedures. Rotted xylopodia should be discarded as soon as the rot is noted.

The presence of white mold, which was identified as fusarium and rhizoctonia, should be washed off as soon it is observed and the xylopodia returned to the place where they are kept. Fusarium, a large genus of filamentous fungi, is widely distributed in soil and in association with plants. Most species are harmless members of the soil microbial community. Rhizoctonia is a genus of anamophic fungi that do not produce spores but are composed of hyphae and sclerotia. We did not correlate white mold occurrence to rot, but it appears to be beneficial to remove it. Mold washes easily from the surface of the xylopodia.

Root emergence is not an indicator of plant emergence. Some xylopodia contained only roots and no stems. However, xylopodia rooting was noted on all the emerged plants. Therefore, when conducting this technique, rooted xylopodia should be watched closely, especially after 68 and up to 114 days or longer after removal from the root system. However, the presence of rooting does not necessarily mean a new sprout in the future.

We found propagating C. fragrans is possible in a controlled greenhouse environment and has the potential to increase plant numbers in the field. Propagating C. fragrans is a viable method for remediation. The plants produced have the physiological attributes (roots, whole leaves, and turgid xylopodia) for transplanting. Vegetative propagation is beneficial as compared to sexual reproduction because of the difficulty in collecting viable seeds and in the maintenance of genetic structure. Also, the plants maintained in the greenhouse appear to have many more xylopodia than plants from the field. Since xylopodia is a source of new plants, this technique may be more beneficial than seed collection to increase plant populations in the field. 


\section{References}

Christman, S. P., and W. S. J udd. 1990. Notes on plants endemic to Florida scrub. Florida Scientist 53: 52-73.

Fantz, P. R. 1977. A monograph of the genus Clitoria (Leguminosae: Glycineae). PhD dissertation, University of Florida, Gainesville.

Gravel, V., H. R. Antoun, and J .Tweddell. 2007. Growth stimulation and fruit yield improvement of greenhouse tomato plants by inoculation with Pseudomonas putida or Trichoderma atroviride: Possible role of indole-3- acetic acid (IAA). Soil Biology \& Biochemistry 39:1968- 1977.

Lewis, M. 2007. Life history and reproductive biology of Clitoria fragrans relative to fire history on the Avon Park Air Force Range. M.S. Thesis, University of Central Florida.

Ludwig-Müller, J. 2000. Indole-3-butyric acid in plant grouth and development. Plant Growth Regulation 32:219- 230.

Palazzo, A. J., S. E. Hardy, T. J . Cary, and T.L. Bashore. 2006. A review of the growth habits and restoration issues for Clitoria fragrans and Polygonella basiramia. ERDC/ CRREL TR-07-6. Hanover, NH: U.S. Army Engineer Research and Development Center.

Palhares, D., J . E. de Paula, L. A. R. Pereira, and C. E. S. Silveira. 2007. Comparative wood anatomy of stem, root, and xylopodium of Brosimumgaudi chaudii (Moraceae). IAWA J ournal 28 (1): 83-94.

Simon, S., and J . Petrášek. 2011. Why plants need more than one type of auxin. Plant Science 180:454-460

Starbuck, E. J ., and J. L. Preczewski. 1986. Effect of root-applied IBA on root and shoot growth of dwarf peach trees. J ournal of Environmental Horticulture 4 (3): 8082.

U.S. Air Force (USAF). 2004. Integrated Natural Resources Management. Air Force Instruction 32-7064. http://static.e-publishing.af.mil/production/1/shawafb/publication/ afi32-7064_shawafbsup_i/afi32-7064_shawafbsup_i.pdf (accessed 6 February 2014).

U.S. Congress. 1973. Endangered Species Act. Codified at 16 U.S.C. 1531 (et seq.). Washington, DC: U.S. Government Printing Office.

U.S. Fish and Wildlife Service (USFWS). 1993. Final rule: Endangered or threatened status for seven central Florida plants. Federal Register 58 (79): 25746-24755. Published April 27.

U.S. Fish and Wildlife Service (USFWS). 1999. Multi-species recovery plan for South Florida (Revised). Atlanta, GA: U.S. Fish and Wildlife Service. 
Weekley, C. W., and E. S. Menges. 2003. Species and vegetation responses to prescribed fire in a long-unburned, endemic-rich Lake Wales Ridge Scrub. J ournal of the Torrey Botanical Society 130:265- 282.

Wallnöfer, B. 1997. A revision of Styrax L. Section Pamphilia (Mart. ex A.DC.) B. Wallin. (Styracaceae). Annalen des Naturhistorischen Museums in Wein 99B:681- 720.

Wunderlin, R. P., D. Richardson, and B. Hansen. 1980. Status report on Clitoria fragrans. Unpublished report. Vero Beach, FL: U.S. Fish and Wildlife Service.

Zhao, Y. 2010. Auxin biosynthesis and its role in plant development. Annual Review of Plant Biology 61:49-64. 


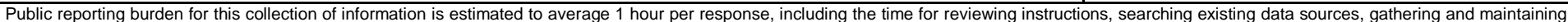

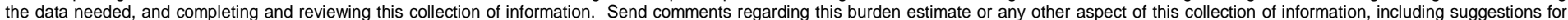

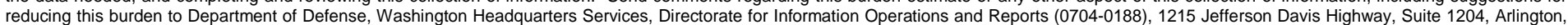

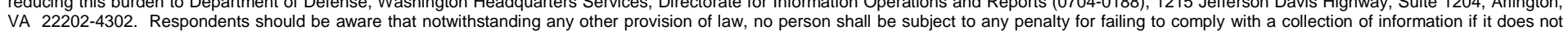
VA 22202-4302. Respondents should be aware that notwithstanding any other provision of law, no person shall be sube
display a currently valid OMB control number. PLEASE DO NOT RETURN YOUR FORM TO THE ABOVE ADDRESS.
1. REPORT DATE (DD-MM-YYYY)
March 2015

4. TITLE AND SUBTITLE

A Technique to Propagate Clitoria fragrans from Xylopodia
3. DATES COVERED (From - To)

5a. CONTRACT NUMBER

5b. GRANT NUMBER

5c. PROGRAM ELEMENT NUMBER

5d. PROJECT NUMBER

F2QF270137G002

5e. TASK NUMBER

5f. WORK UNIT NUMBER

8. PERFORMING ORGANIZATION REPORT NUMBER

ERDC/CRREL TR-15-5

Cold Regions Research and Engineering Laboratory (CRREL)

U.S. Army Engineer Research and Development Center (ERDC)

72 Lyme Road

Hanover, NH 03755-1290

9. SPONSORING I MONITORING AGENCY NAME(S) AND ADDRESS(ES)

10. SPONSOR/MONITOR'S ACRONYM(S)

Ranges, Airspace and Airfield Operations Division

Headquarters Air Combat Command

Langley Air Force Base, VA 23665-2789
11. SPONSOR/MONITOR'S REPORT NUMBER(S)

\section{DISTRIBUTION / AVAILABILITY STATEMENT}

Approved for public release; distribution is unlimited.

\section{SUPPLEMENTARY NOTES}

\section{ABSTRACT}

Clitoria fragrans (pigeon wings), is a limited seed producer and a federally listed threatened plant. Therefore, we conducted a greenhouse study to determine whether $C$. fragrans can be propagated vegetatively from xylopodia and whether growth hormones can enhance propagation success. This information could be used to maintain population viability in the future. For this study, we collected mature plants from the field, transplanted them in the greenhouse, and harvested xylopodia from the root system. We treated the xylopodia with indole-3-acetic acid (IAA) or indolebutyric acid (IBA) at concentrations of 0, 250, 500, 1000, and 2000 mg/L for the lateral root xylopodia and at 0 and $1000 \mathrm{mg} / \mathrm{L}$ IAA for the terminal xylopodia. We observed the xylopodia for 114 days for signs of root growth, newly developed shoots, mold, and rot. Lateral xylopodia controls and those treated with IAA produced new plants, though propagation was inversely proportional to the treatment level of IAA. Two of the nine treated terminal xylopodia produced new plants. No plants were propagated from the IBA treatments. Propagating $C$. fragrans is possible and has potential to be a viable method for reestablishing the plant in the field. A total of 19 plants were produced in this study from only two initial $C$. fragrans plants.

\begin{tabular}{|ll|}
\hline 15. SUBJECT TERMS & Habitat management \\
Clitoria fragrans & Pigeon wings \\
Conservation & Propagation \\
\hline
\end{tabular}

16. SECURITY CLASSIFICATION OF:

\section{a. REPORT}

Unclassified

\section{b. ABSTRACT}

Unclassified c. THIS PAGE

Unclassified
Propagation

Unclassified

\begin{tabular}{|c|c|}
$\begin{array}{c}\text { 17. LIMITATION } \\
\text { OF ABSTRACT }\end{array}$ & $\begin{array}{c}\text { 18. NUMBER } \\
\text { OF PAGES }\end{array}$ \\
\cline { 2 - 3 } & 19 \\
\end{tabular}

Threatened and Endangered Species Xylopodia 19a. NAME OF RESPONSIBLE PERSON

19b. TELEPHONE NUMBER (include area code) 